\title{
PENGARUH LEMBAR KERJA SISWA (LKS) BERBASIS PENDEKATAN INDUKTIF TERHADAP HASIL BELAJAR SISWA KELAS X PADA MATERI HUKUM-HUKUM DASAR KIMIA DI SMAN 1 SUNGAI TABUK
}

\section{The Effect of Inductive Approach Based Students' Worksheet on Student's Learning Outcomes in Class X at Basic Chemistry Laws in SMAN 1 Sungai Tabuk}

\author{
Nur Islamiah, Herlina Apriani, Novrian Dony \\ Program Studi Pendidikan Kimia Fakultas Keguruan dan Ilmu Pendidikan \\ Universitas Islam Kalimantan (Uniska) Muhammad Arsyad Al Banjari, Banjarmasin \\ *e-mail: Nurislamiah85@gmail.com
}

\begin{abstract}
Abstrak. Penelitian ini bertujuan untuk mengetahui pengaruh lembar kerja siswa (LKS) berbasis pendekatan induktif terhadap hasil belajar siswa kelas X pada materi hukum-hukum dasar kimia di SMAN 1 Sungai Tabuk tahun pelajaran 2018/2019. Penelitian ini dilaksanakan di SMAN 1 sungai tabuk dengan menggunakan metode quasy eksperimen yang melibatkan dua kelompok yaitu kelas eksperimen dan kelas kontrol menggunakan desain nonequivalent pretest posttest kontrol group design. Sampel dalam penelitian ini adalah siswa kelas $\mathrm{X}$ MIA SMAN 1 Sungai Tabuk berjumlah 69 sampel yang terdiri dari kelas eksperimen berjumlah 36 siswa dan pada kelas kontrol berjumlah 33 siswa. Instrumen pengumpulan data menggunakan soal tes pretest dan posttest. Hasil analisis data menggunakan uji Mann-whitney diperoleh nilai signifikansi sebesar 0,000 yang menyatakan $\mathrm{H}_{1}$ diterima sehingga kesimpulan dari penelitian ini adalah terdapat pengaruh LKS berbasis pendekatan induktif terhadap hasil belajar siswa
\end{abstract}

Kata kunci: LKS, Pendekatan Induktif, Hasil belajar, Hukum-hukum dasar kimia

\begin{abstract}
This study aimed to determine the effect of students' worksheets based on inductive approach towards student's learning outcomes in class $X$ at basic chemistry law material in SMAN 1 Sungai Tabuk in the academic year of 2018/2019. This research was conducted in SMAN 1 Sungai Tabuk by using quasi experiment method that involved two groups which were experimental class and control class using nonequivalent pretest posttest control group design. The sample in this research was students of class X MIA SMAN 1 Sungai Tabuk as many as 69 people that consisted of 36 students in experimental class and 33 students in control class. Data collection instruments were pretest and posttest questions. The nalyzed results data which was a by using the Mann-whitney test in which it obtained a significance value of 0,000 which stated that $H_{1}$ was accepted so the conclution of this study there was effect of students' worksheets based on inductive approach towards student's learning outcomes.
\end{abstract}

Keywords: Worksheet, Inductive Approach, Learning outcomes, Basic laws of chemistry 


\section{PENDAHULUAN}

Pendidikan adalah suatu proses yang dapat dipilih untuk meningkatkan ilmu pengetahuan, keterampilan dan keagamaan.. Proses pendidikan diharapkan agar dapat menyiapkan serta menghasilkan sumber daya manusia yang berkualitas agar dapat memproses informasi dengan baik dan benar. Pendidikan memiliki beberapa komponen yaitu tujuan, materi pelajaran, metode dan media pembelajaran. Komponen tersebut sangatlah penting untuk menentukan berhasilnya pendidikan dalam pembelajaran yang optimal.

Kimia adalah cabang ilmu IPA yang berkaitan dengan studi tentang struktur, komposisi, sifat dan reaksi materi. Kimia berisi fenomena dan aktivitas eksperimen yang menarik serta pengetahuan yang bermanfaat untuk memahami alam maupun dunia industri (Aniodoh dan Egbo, 2013). Salah satu materi dalam pelajaran kimia adalah hukum dasar kimia. Materi hukum dasar kimia dalah materi pelajaran kimia yang terdapat dikelas $\mathrm{X}$ genap. Karakteristik materi ini adalah bersifat abstrak, memerlukan kemapuan pemahaman, menghafal, menghitung dan menganalisis serta keaktifan siswa untuk berlatih sehingga siswa benar-benar memahami konsep.

Pembelajaran berlangsung sebagai suatu proses saling mempengaruhi antara guru dan siswa. Proses belajar mengajar ada lima komponen yang sangat penting yaitu tujuan, materi, metode, media dan evaluasi pembelajaran. Kelima aspek ini saling mempengaruhi. Pemilihan salah satu metode mengajar tertentu akan berdampak pada jenis media pembelajaran yang sesuai, dengan tanpa melupakan tiga aspek penting lainnya yaitu tujuan, materi dan evaluasi pembelajaran (Falahudin, 2014)

Proses pembelajaran kimia bertujuan untuk mempersiapkan siswa agar bisa menghadapi perubahan-perubahan keadaan dalam kehidupan melalui pemikiran yang logis, kritis, kreatif dan efektif. Oleh sebab itu, guru dituntut untuk dapat melakukan berbagai usaha perbaikan dalam proses pembelajaran kimia. Dengan aktif dan kreatifnya siswa mengikuti pembelajaran kimia, maka diharapkan hal itu akan memberikan efek positif terhadap hasil belajar yang diperolehnya.

Berdasarkan hasil wawancara sebagai calon guru kimia, di SMAN 1 Sungai Tabuk yang terjadi di lapangan masih jauh dari harapan yang ada. Diketahui hasil ujian siswa pada semester ganjil mata pelajaran kimia rendah, hal ini dapat dilihat dari hasil ujian siswa dengan standar ketuntasan 70 . Masih banyak siswa yang belum mencapai nilai standar keuntasan tersebut. Menurut guru pun siswa masih banyak yang kurang memahami dalam menentukan hukum perbandingan maupun berganda. Sehingga dapat dikatakan bahwa siswa mengalami kesulitan dalam memahami materi hukum dasar kimia.

Rendahnya hasil ketuntasan siswa karena pada saat proses belajar mengajar berlangsung siswa kurang memperhatikannya dan juga hanya berpusat pada guru membuat siswa belum dapat menangkap makna dari apa yang diperoleh dari pembelajaran untuk dapat diterapkan dalam kehidupan sehari-hari sehingga siswa merasa bosan dan kesulitan dalam mempelajari pelajaran kimia karena dianggap tidak manfaat praktis dalam kehidupan sehari-hari. Kondisi seperti ini mengharuskan guru memiliki kemampuan merancang pembelajaran untuk membekali pengetahuan secara teoritis maupun praktek kepada siswa dan menciptakan kondisi belajar yang efektif sehingga lebih mudah untuk memahami, memaknai serta menghubungkan materi 
pelajaran yang mereka pelajari dengan kehidupan nyata. Oleh karena itu, maka pembelajaran dengan pendekatan induktif bagi peneliti dirasa cocok untuk mengatasi masalah tersebut karena pembelajaran tersebut dapat melatih siswa membentuk dan bisa untuk menarik kesimpulan berdasarkan dari contoh-contohnya (Soedjana,2000). Pembelajaran ini juga mengarahkan perhatian siswa agar fokus tidak hanya pada logika, tetapi juga pada pengetahuan.

Pendekatan induktif ini dituangkan dalam bentuk LKS untuk memaksimalkannya. LKS merupakan panduan siswa yang biasa digunakan dalam kegiatan observasi, eksperimen, maupun demontrasi untuk mempermudah proses penyidikan atau memecahkan masalah ( Trianto, 2011). Lembar kerja siswa (LKS) berbasis pendekatan induktif ini diharapkan dapat membuat siswa lebih aktif dengan materi yang dibahas dan memberikan pengalaman belajar siswa saat pengerjaan latihan soal. Supaya siswa mampu mengatasi masalah dalam pembelajaran sehingga mampu mengkontruksikan sendiri pengetahuannya. Berdasarkan uraian diatas. Maka, perlu dilakukan penelitian "Pengaruh Lembar Kerja Siswa (LKS) Berbasis Pendekatan Induktif terhadap hasil belajar siswa kelas $\mathrm{X}$ pada materi hukum-hukum dasar kimia di SMAN 1 Sungai Tabuk".

\section{METODE PENELITIAN}

Penelitian ini menggunakan jenis quasy eksperimen dengan desain penelitian nonequivalent pretest posttest kontrol group design. Penelitian ini bertempat di SMAN 1 Sungai Tabuk dimana menggunakan dua sampel yaitu kelas X MIA 1 dan kelas X MIA 2 dari populasi seluruh siswa kelas X MIA di SMAN 1 Sungai Tabuk yang berjumlah 69 siswa. Sampel merupakan bagian dari populasi (Sugiyono, 2012).

Variabel yang akan diteliti dalam penelitian ini terdiri dari variabel bebas adalah Lembar Kerja Siswa (LKS) berbasis pendekatan induktif, variabel terikatnya adalah hasil belajar sebagai suatu atribut atau sifat atau nilai dari orang, objek atau kegiatan yang mempunyai variasi tertentu yang ditetapkan oleh peneliti untuk dipelajari dan kemudian ditarik kesimpulan (Sugiyono, 2012).

Teknik pengambilan sampel menggunakan teknik cluster sampling, dimana kelas X MIA 1 sebagai kelas eksperimen dan kelas X MIA 3 sebagai kelas kontrol. Teknik pengumpulan data menggunakan instrumen penelitian, yaitu tes hasil belajar berupa soal tes sebanyak 20 butir untuk masing-masing soal pretest dan posttest. Teknik analisis data yang digunakan untuk uji prasyarat adalah uji normalitas dan uji homogenitas kedua uji ini bertujuan untuk mengetahui apakah ada atau tidaknya perbedaan pada hasil penelitian kedua sampel tersebut.

Setelah mengetahui uji normalitas dan uji homogenitas, maka dilakukan uji hipotesis yaitu menggunakan uji mann-whitney yang digunakan menggunakan aplikasi spss tipe 16 dengan kriteria yaitu jika sig $>0,05 \mathrm{H}_{0}$ diterima dan $\mathrm{Ha}$ ditolak kemudian jika sig $<0,05$ maka $\mathrm{H}_{0}$ ditolak dan Ha diterima (Sarwono, 2012).

\section{HASIL DAN PEMBAHASAN}

Pada penelitian ini, instrumen yang digunakan dalam penelitian melalui uji kelayakan instrumen atau uji validitas butir soal terlebih dahulu. Uji validitas butir soal yang dilakukan terhadap 23 siswa kelas XI Ipa 3 di SMAN 1 Sungai Tabuk. Uji validitas ini digunakan untuk mengetahui valid atau tidaknya soal yang akan digunakan dalam 
penelitian. Soal yang di uji cobakan berupa soal pilihan ganda dengan 5 pilihan yang berjumlah 25 soal. Dimana dari 25 soal yang diuji cobakan didapatkan hasil 21 yang valid dan 4 soal yang tidak valid.

Uji coba instrument selanjutnya adalah uji reliabilitas, uji releabilitas ini digunakan untuk mengetahui apakah reliable tidaknya soal yang akan digunakan dalam penelitian. Dari 21 soal yang valid dihitunglah reliabilitasnya dan didapatkan hasil sebesar 0,637. sig > 0,05 dikatakan rebilitas dan data tidak reabilitas jika nilai sig $<0,05$ menurut Ghozali (2013).

Uji tingkat kesukaran soal, pada uji ini didapatkan 2 soal masuk dalam kategori sangat mudah, 8 soal masuk dalam kategori mudah dan 11 soal dalam kategori sedang. Kriteria tingkat kesukaran (Arikunto, 2010): Menurut kriteria yang sering di ikuti indeks kesukaran sering di klasifikasikan sebagai berikut. Apabila soal dengan $\mathrm{P}$ reng indeks kesukaran $0-30 \%$ adalah soal kategori sukar, $31 \%-70 \%$ adalah soal kategori sedang sedangkan untuk $71 \%-100 \%$ adakah soal kategori mudah.

Uji daya pembeda soal, dari hasil uji coba didapatkan hasil 5 soal dalam kategori sangat baik, 8 soal dalam kategori baik, 4 soal dalam kategori cukup dan 4 soal dalam kategori jelek. Kriteria untuk mengetahui daya beda butir soal adalah Jika $0,00<\mathrm{D} \leq$ 0,20 adalah item yang jelek, $0,20<\mathrm{D} \leq 0,40$ adalah item yang cukup, $0,40<\mathrm{D} \leq 0,70$ adalah item yang baik , $0,70<\mathrm{D} \leq 1,00$ adalah item yang baik sekali (Arikunto;2010).

Untuk mengetahui apakah terjadi peningkatan maka perlu dilakukan uji hipotesis. Sebelum dilakukan uji tersebut maka dilakukan uji prasyaratnya dulu yaitu uji normalitas dan uji homogenitas menggunakan aplikasi Spss v 16. Sehingga didapat nilai untuk uji normalitas pada kelas eksperimen sebesar 0,002 yang berarti nilai signifikannya lebih kecil dari nilai alpa 0,05 sehingga data hasil belajar dari kelas eksperimen ini bisa dikatakan berdistribusi tidak normal. Kemudian untuk kelas kontrol diperoleh nilai sebesar 0,000 yang berarti nilainya signifikan lebih kecil dari nilai alpa 0,05 sehingga data hasil tersebut juga dikatakan berdistribusi tidak normal.

Berdasarkan hasil dari perhitungan uji normalitas didapatkan bahwa sebaran data terhadap kedua kelas adalah tidak terdistribusi normal. Tahap selanjutnya untuk mengetahui uji beda dua rata-rata untuk data posttest dari kedua kelas menggunakan uji statistik nonparametrik yaitu uji Mann-Whithney U. Hasil output uji hipotesis menggunakan uji Mann-Whithney U dapat dilihat pada gambar 1 berikut ini.

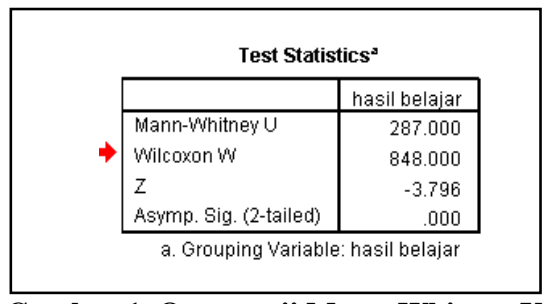

Gambar 1. Output uji Mann-Whitney U

Dari gambar 1 diatas bisa dilihat bahwa uji hipotesis dilakukan karna data hasil uji normalitas dan homogenitas adalah berdistribusi normal dan juga homogen. Maka nilai signifikan pada kelas eksperimen 0,000 dan Ha diterima. Sig $<0,05$ data dapat diterima dan tidak diterima jika nilai sig >0,05 menurut Ghozali (2013). Maka bisa dikatakan bahwa ada pengaruh LKS berbasis pendekatan induktif terhadap hasil belajar 
siswa kelas X pada materi hukum-hukum dasar kimia di SMAN 1 Sungai Tabuk. Hasil ini senada dengan penelitian yang dilakukan oleh Nurliawati (2016) yang menyatakan bahwa menggunakan media LKS dapat meningkatkan hasil belajar.

Selain menggunakan uji Mann-Whitney U, perbedaan hasil belajar siswa kelas eksperimen dan kelas kontrol juga dapat dilihat pada perbandingan nilai pretest dan ppostest kedua kelas. Perbedaan skor pretes dan postest siswa pada kelas eksperimendan kelas kontrol bisa dilihat dari data pada tabel 1 .

Tabel 1. Perbedaan skor siswa kelas eksperimen dan kontrol

\begin{tabular}{lll}
\hline Komponen & Kelas kontrol & Kelas eksperimen \\
\hline Pretest & $56,21 \%$ & $52,25 \%$ \\
Posttest & $73,33 \%$ & $76,25 \%$ \\
Jumlah siswa & 33 & 36 \\
\hline
\end{tabular}

Dari tabel 1 diatas bahwa hasil awal penelitian didapatkan dari hasil pretest yaitu dengan tes dan diberikan perlakuan. Dan data akhir didapatkan dari posttest yang dilakukan setelah diberi perlakuan dengan media LKS untuk kelas eksperimen dan konvensional untuk kelas kontrol. Yang didapatkan hasil rata-rata nilai pretest untuk kelas eksperimen sebesar $52,25 \%$ dan nilai posttest nya sebesar $76,25 \%$, untuk kelas kontrol nilai pretest sebesar $56,21 \%$ dan nilai posttest sebesar 73,33\%. Dari nilai tersebut dapat diketahui bahwa terdapat kenaikan rata-rata pada kelas kontrol maupun kelas eksperimen.

Penggunaan LKS berbasis pendekatan induktif adalah satu faktor yang membuat pembelajaran lebih aktif. Pembelajaran dengan menggunakan LKS berbasis pendekatan induktif menjadikan siswa lebih aktif, sehingga siswa terampil dalam berpikir. Hal ini sesuai dengan penelitian yang dilakukan oleh Khairiyah dkk (2019) bahwa dengan menggunakan LKS berbasis pendekatan induktif dapat meningkatkan kemampuan berpikir kritis siswa. Berdasarkkan hasil penelitian Siswanto (2012) pembelajaran dengan menggunakan LKS berbasis pendekatan induktif memberikan pengaruh lebih baik terhadap kempuan berpikir kritis dan kreatif siswa.

Hasil penelitian ini hanya berfokus pada hasil belajar siswa. Hasil belajar yang diharapkan dapat tercapai pada penelitian ini adalah hasil penelitian dalam ranah pemahaman, pengetahuan dan penerapan. Dengan adanya penelitian ini diharapkan siswa dapat menjadi lebih aktif dalam proses pembelajaran. Penggunaan LKS dapat menghasilkan respon yang baik. Respon tersebut adalah hasil belajar. Hasil belajar pada kelas eksperimen yang menggunakan LKS dan pada kelas kontrol yang tidak menggunakan LKS memiliki perbedaan.

\section{SIMPULAN}

Berdasarkan hasil dan pembahasan yang telah dipaparkan dapat diambil kesimpulan bahwa terdapat pengaruh LKS berbasis pendekatan induktif terhadap hasil belajar siswa pada materi hukum-hukum dasar kimia kelas X di SMAN 1 Sungai Tabuk.

\section{DAFTAR RUJUKAN}


Dalton : Jurnal Pendidikan Kimia dan Ilmu Kimia, Volume 3 Nomor 2, November 2020

Aniodoh, H. C. O. dan Egbo, J. J. (2013). Effect of Gender on Student' Achievement in Chemistry Using Inquiry Role in Instructional Model. Journal of Educational and Social Research. 3 (6): 17-21.

Arikunto. (2010). Dasar-Dasar Evaluasi Pendidikan. Jakarta : PT Bumi Aksara.

Falahudin. I. (2014). Pemanfaatan Media Dalam Pembelajaran. Jurnal Lingkar Widyaiswara, 1(4), 104-117.

Ghozali, I. (2013). Aplikasi Analisis Multivariate dengan Program SPSS. Edisi Ketujuh. Semarang : Badan Penerbit Universitas Diponegoro.

Khairiyah, R. S., Wardhani, R. R. A. A. K., Apriani, H. (2019). Pengaruh LKS Berbasis Pendekatan Induktif Terhadap Kemapuan Berpikir Kritis Siswa Pada Materi Kelarutan dan Hasil Kelarutan Di SMA 12 Banjarmasin. Dalton:Jurnal Pendidikan Kimia dan Ilmu Kimia, 2(1), 11-15.

Nurliawati, N. (2016). Pengaruh Penggunaan LKS Berbasis Komik Terhadap Hasil Belajar siswa Kelas VIII Di MTSS Insan Qur'ani Pada Materi Cahaya. Skripsi. Banda Aceh: Universitas Islam Negeri Ar-Raniry Darussalam

Sarwono, J. (2012). IBM SPSS “Advancees Statistic”. Prosedur-prosedur Generalisasi dan Perluasan General Linear Model (GLM). Yogyakarta: ANDI.

Siswanto, J. (2012). Pengaruh Penggunaan Lembar Kerja dengan Pendekatan Induktif Terhadap Kemampuan Berpikir Kritis dan Kreatif Siswa dalam Pembelajaran Fisika. Skripsi. Semarang: IKIP PGRI Semarang.

Sugiyono. (2012). Metode Penelitian Kualitatif Kuantitatif dan R\&D. Bandung: Alfabeta.

Trianto. (2011). Mendesain Model Pembelajaran Inovatif-Progresif. Prestasi Pustaka. Jakarta. 